\title{
Instructional Development in Canadian Higher Education
}

\author{
BRUCE M. SHORE*
}

Canadian universities and colleges are in the forefront of worldwide efforts by educational institutions to improve the quality of teaching and learning. This striving for improvement, very simply, is what instructional development means.

The idea of instructional development appears in different contexts. It sometimes has the connotation of staff development. This would be an incomplete definition, because it is not always the skills and knowledge of the teaching staff that require attention. Other parts of the educational process can be implicated, such as the quality of instructional materials, the physical plant, or the relative value placed on teaching by the institution. Another topic which frequently turns up in the same sentence with instructional development is evaluation. This may be the evaluation of students' learning, of instructors' teaching, or both. Again, instructional development activities at a particular institution may or may not include these. Evaluation and staff development are examples, important examples, of instructional development.

The question that universities and colleges have to answer is how they will provide for instructional development. Some leave it to chance. Some set up committees or ask a seemingly appropriate unit such as a counselling service to operate workshops. A few assign an individual coordinating responsibilities. These individuals are sometimes senior academic officers, sometimes specialists such as Staff Development Officer or Director of Pedagogical Services. Finally, a growing number of institutions have established pedagogical service units, of various sizes, charged with relatively broad ranges of instructional development activities.

Audiovisual and media centres are usually excluded from definitions of instructional development. Their exclusion might be only partly justifiable, but it is based on the degree of initiative exercised by the centre in carrying out its mandate. Media centres tend to be exclusively responsive to requests. Although they will frequently counsel an instructor about the appropriateness of a medium he or she has selected, in general if the instructor wants slides (or whatever) and provides an active account number, slides will be produced. Instructional development centres are also designed to be responsive

${ }^{1}$ This paper is based largely on "The Growth of Instructional Development in Canadian Higher Education since 1969," presented at the Annual Meeting of the Canadian Society for the Study of Higher Education, Toronto, June 1974. I thank my colleague Janet Donald for her comments on the manuscript.

*Associate Professor, Centre for Learning and Development and Department of Educational Psychology and Sociology, McGill University. 
to instructors' requests, but not exclusively. They frequently take much more initiative in selecting whom they will serve and in what way. They are also relatively free of commitments to either hardware or any specific set of instructional techniques (e.g., television or computer-assisted instruction). They would, however, counsel an instructor in the effective use of any of these, and probably be involved in their development and validation on the campus.

The purpose of this paper is to discuss the growth of these pedagogical services in Canada from four points of view: first, the obvious growth in numbers; second, the range of activities being undertaken; third, the growth of a community of instructional development centres; and, finally, the future of such services in this country.

\section{The Spread of Instructional Development Agencies}

In 1969 an old, traditional, and respected Canadian university stuck its neck out just a little bit and charged a small group of its members with the responsibility of providing instructional development resources to the university community. And so was founded the Centre for Learning and Development (CLD) at McGill. Our present concern is what has occurred elsewhere and since across Canada.

In the spring of 1974, there were formal agencies or standing committees at more than 13 universities and 65 colleges, plus two created to serve several campuses. This is undoubtedly an underestimate, and does not take account of dozens of individuals with other titles who fulfill some of these functions, nor agencies serving only single faculties. Earlier last winter CLD polled every college, university, and relevant government and association office across the country. ${ }^{2}$ The product was a 41 -page first version of an Index to Pedagogical Services in Canadian Universities and Colleges containing over 270 names of offices and concerned individuals. ${ }^{3} \mathrm{~A}$ follow-up request for more information was sent out in April 1974. We have now begun to prepare an annotated directory of these instructional development services. The following remarks are based upon a first examination of the replies.

The most striking feature of the growth of these services is its irregularity. Here are some examples. Community colleges have expanded more quickly than universities in providing formal instructional development services; services are found in colleges in every province. Second, colleges are more likely than universities to appoint an official to coordinate these activities. They have titles such as Director of In-Service Training, Staff or Educational Development Officer, and Directeur des Services pédagogiques. Universities still tend to have committees, and several of these are planning committees considering the formation of centres rather than actually providing services. A third irregular feature is the regional disparity in the extent to which the idea has caught on.

2I am grateful to research assistants Paul Schnall and Anne Dychtenberg for their efforts in conducting the surveys on which this report is partly based, and to Anne Sage and Mary Cerre for their clerical assistance.

${ }^{3}$ Shore, Bruce M., and Donald, Janet G. Index to Pedagogical Services in Canadian Universities and Colleges. Centre for Learning and Development, McGill University, Montreal, 1974. (This limited edition is out of print, and will be replaced late in 1974 by an annotated directory of such services in Canada. A directory of other major centres around the world is also in preparation, and is expected to be available in 1975.) 
Quebec had pedagogical services in its four largest universities before any other university in the country. Only the Atlantic Institute of Education preceded three of them, with instructional development services to colleges and universities being only one part of an extensive mandate.

Ontario had a few units, but took its first big step with the founding of the Ontario Universities Programme for Instructional Development last year.* Very little has happened at the universities west of the Laurentian Shield. There are active individuals, for example, on most western campuses, but centres and even service committees do not exist except at Athabaska. One university which shall remain nameless has actually been sitting on a report calling for the establishment of a pedagogical service centre for nearly four years.

What are the reasons for this irregular growth in numbers, and the hesitancy to take the step of institutionalizing instructional development? We can begin by rejecting a few possible answers.

The first is that providing such services invades academic freedom. There certainly are grounds for suggesting such an answer. Colleges have moved much more quickly than universities in establishing formal services, and college instructors have a narrower range of responsibilities than university professors. Put another way, teaching is a smaller part of the total work of the average university than college instructor, whatever might be regarded as average or typical. The other activities of university professors, in particular, are endowed with a heritage of freedom of choice and inquiry. The demand for such things as mission-oriented or mission-relevant research, taken up by some granting agencies, is seen as enough of an encroachment. "At least leave me alone with my teaching," is not an unheard rejoinder. Nevertheless, most professors are sufficiently impressed by the demands of teaching to large and heterogeneous numbers of students that they are willing to more than tolerate assistance in pedagogy. There have also always been many professors who take great pride in their teaching and are eager to add to their teaching skills. As long as using instructional development services is voluntary, no threat to academic freedom exists.

Lack of concern in one region or another also does not explain the irregular growth. There are people on every campus in the country, and in other organizations from the Canadian Association of University Teachers and the Association of Universities and Colleges of Canada to Statistics Canada, who are committed to the improvement of teaching and learning in higher education.

There are really only two reasons that matter. The first is internal politics, and the second is money. Let us deal with the question of finances first. What does it cost to mount a formal instructional development service?

We are in the process at CLD of developing guidelines for starting a new pedagogical service. ${ }^{4}$ We hope to have this completed in the next few months, but have so far agreed on a few basic principles. First, some critical mass is required. An instructional develop-

*See Harold M. Good and Bernard Trotter, "Accountability for Effective and Efficient University Teaching," Stoa, IV, 1.

${ }^{4}$ Geis, George L., and Shore, Bruce M. "Dimensions of Instructional Development Services: Prescription." Paper presented at the Annual Meeting of the National Society for Performance and Instruction, Miami, April 1974. 
ment agency cannot be handled by one person. The job involves challenging a very personal part of a professor's work, namely teaching, and it is very easy to make enemies. One always does so while accumulating the experience that comes with the first few errors, and it is nice to have a shoulder to cry on. The need to tread softly is learned quickly.

At the very least, then, two professors and some clerical help are going to cost thirtyfive to forty thousand dollars at the minimum, excluding overhead and postage stamps. Fifty thousand is probably an appropriate round start-up figure. How would that compare to the annual costs of running a university? Using McGill as an example, the annual operating budget (1974-75) is in the neighborhood of sixty-five million dollars. Fifty thousand would be $0.077 \%$ of the operating budget. If other universities and colleges cost a half or quarter as much to operate as McGill, that ratio could be doubled or quadrupled to $0.15 \%$ or $0.3 \%$ of the total operating budget. It is somewhat mindboggling to imagine a successful business in the high technologies, or the like, contributing one-third of one per cent of its operating budget to development in the one of its activities that is the primary source of those very revenues, or at least a major basis for their allotment. It seems prudent to keep in mind that both universities and colleges receive operating funds as teaching institutions, and it is the invisible activities of research and scholarship that compete to some extent elsewhere for support. Undergraduate enrolment matters.

The question of what one can buy for $\$ 50,000$ shall remain open for the moment; we will discuss in more detail what pedagogical services do. We will also take our own university off the hook to some extent. McGill will directly spend about one-third of a million dollars on instructional development next year, and it is possible that this expenditure could rise more quickly than the overall budget. This amount is about one-half of one per cent of the operating budget. Quebec's CEGEPs tend to have around one per cent of their budgets allocated for teaching improvement services, but each college may exercise discretion in how to spend it and not all choose to have centres. What is an ideal amount? Manitoba's Oliver Report ${ }^{5}$ recommended three per cent. We all have some way to go.

In any case, even though fifty, a hundred, or three hundred thousand dollars is a mere drop in the bucket, we have to concede that it is a big thing to the other drops. Fifty thousand dollars is a lot of money to a chairman told he cannot fill that vacancy in his department. Here is where we come to politics.

Where instructional development centres and committees exist, they are new and, hence, the proverbial low-men on the totem-pole. The provision of pedagogical services in Quebec, in fact, has achieved a unique sign of its development, namely the first loss of a pedagogical service in one of the CEGEPs. Where services do not exist they face similar competition for drying up dollars. This explanation fits the facts very well. In Quebec, where enrolments have continued to climb, and are now only levelling off rather than declining, and where a financing formula less closely tied to enrolments has prevailed, services have mushroomed. In addition, and most important, the senior academic officers have themselves been convinced of the value of such services. Any campus with a prayer of starting a service very much needs a guardian angel in the front office. In the absence

${ }^{5}$ Oliver, Michael, et al. Post-Secondary Education in Manitoba: Report of the Task Force. Department of Colleges and Universities Affairs, Government of Manitoba, Winnipeg, 1973. 
of a guardian angel, a vice-principal will do. In Quebec we had the further advantage of regular meetings of these people, at the Conference of Rectors and Principals, where it was possible to engage in extensive lobbying and for the universities in turn to pass this pressure on to the government for financial help designated for instructional development. There is still hope for such help in the next year or so.

The numerical growth advantage of instructional development services in the community colleges also fits this money and politics hypothesis. Community colleges have been an educational priority in all parts of Canada for the past five years. The boom may be over, but the CEGEPs, CAATs (Colleges of Applied Arts and Technology, in Ontario) and others are here to stay and thrive. Proponents of instructional development services have ridden that boom successfully.

We have so far left out one part of the money-power equation with which we will conclude our discussion of numerical growth. This variable is student activism. Student pressure was important in securing changes in Canadian universities in the late 1960's. This desire for involvement and opportunities for personal development has since been manifest in the community colleges. Times are quiet in the universities, to a large extent. If such things are cyclical (an open question) then students may again help those who are trying to get institutions to commit hard cash to improving the product the students are receiving.

\section{Instructional Development Activities}

There are many different kinds of instructional development services, ${ }^{6}$ and in conjunction with its guidelines for their establishment, CLD is preparing a typology of formal centres. The emphasis is less on their organization and more on what they actually do in the name of instructional development. Of course, the two are not entirely independent - organization does, thankfully, follow purpose, or perhaps in some cases, the other way around! Canadian pedagogical services vary in size from one to twenty persons. Their status ranges from Senate and Faculty committees to formal organizations resembling academic departments.

Instructional development agencies primarily provide the following services, in various combinations:

- clearing-house for information on various topics

- library for local use, e.g., on innovation

- information dissemination, e.g., publishing a newsletter

- reading and study skills training to students

- ongoing (formative) evaluation of courses

- assistance with course and program planning

- production of "packaged" course materials

- staff workshops on instructional methods

- course evaluations (final or summative)

${ }^{6}$ Geis, George L., and Shore, Bruce M., "Dimensions of Instructional Development Services: Description." Paper presented at the Annual Meeting of the National Society for Performance and Instruction, Miami, April 1974. 
- applied research on learning in higher education

- theoretical research

- lobbying for changes in the reward system for good teaching.

A general purpose centre such as McGill's CLD is active in almost all of these. Smaller centres, particularly in community colleges, tend to specialize in a small cluster of activities, for example, the first few (generally information dissemination) or evaluation and staff workshops. Size is only one of the criteria against which differences in approach may be identified.

Another basis of differences in services provided is the nature of the staff. Members of teaching staff involved in instructional development are more often found doing the services at the beginning and end of the list, namely the library and research types. Maybe these have some kind of special appeal to academics. When the centres are staffed by administrators or technical personnel, the middle services (workshops, course design, and evaluation) seem to be the main services provided. It might be that only such persons, free of the other pressures on academics, are able to devote themselves to the repetitive application required by these services. A general-purpose centre likely requires a differentiated staff. On the other hand a campus may need more than one centre or service. This notion has received considerable support at McGill. In 1970 the Office of Educational Development (OED) was set up to group together a variety of instructional development agencies, beginning with CLD and the media centre. Since then, the OED has itself financially supported specific projects (such as modularization of courses). Most recently, the OED and the Senate Committee on Educational Development, its advisory council, have accepted CLD's proposal of a separate centre, an Instructional Development Service to take the responsibility from CLD for providing services which have already been developed and which can be fairly routinely applied. These services could include most course evaluations, an examination service, and the like. CLD would become more of a Research and Development branch, still involved in day-to-day services, but only in instances where it could learn and form new ideas for application. The two units would work very closely, but whereas CLD is staffed by academics, members of the new laboratory would be more like the high-level technicians and specialists of a media centre.

In order to provide an idea of how this differentiation of services exists across the country, here are some brief examples of other units, their basic organizations, the main services they provide.

At Grande Prairie Regional College, Alberta, the Professional Development Committee is responsible for collecting and disseminating information on seminars and conferences and the like, organizing in-service seminars, and administering the Professional Growth Fund. At Algonquin College of Applied Arts and Technology the Department of Staff Development (two people) organizes workships, circulates articles, and consults with individuals on request. Dawson College in Montreal has a documentation centre which acts as a clearing-house on information about educational innovations. It is also considering a separate centre for personal development of students. The Service pédagogique at Université de Montréal and the Service de Pédagogie universitaire at Université Laval are each organized around specialists assigned to specific services such as measurement 
and testing, course evaluation, and instructional design. Not all their core members are academic members of staff. At l'Université du Québec à Montréal, only the director is. In all four Quebec university services, though, the core staff are academically trained and research figures in all of their organizations to varying degrees.

These examples illustrate two points: first, the differences in approaches at various campuses, and second, the grouping of these activities according to the clusters discussed. It is especially important to note that no one set of activities is best. An instructional development centre must serve locally appropriate needs most directly.

The last activity in the list given earlier, namely, seeking changes in the reward system for effective teaching, seems to be getting the least attention. This is probably because it is such a difficult problem to wrestle with. The problems are compounded when colleges and universities take negative steps first, such as using course evaluation results to fire or not promote people. It is very difficult to convince an instructor to be evaluated in any way for the purpose of improvement when he knows a Promotion and Tenure Committee has recently refused a promotion to a colleague for low ratings on some questionnaire. And that even assumes participation in the evaluation is voluntary. There is a dire need to turn such procedures to positive ends, and one way to accomplish this might be to assign responsibility for all such evaluative procedures to instructional development centres which, independent of the bureaucracy, could refuse to apply them to anything but positive uses. CLD has made a couple of small dents at McGill with the acceptance by the University of two programs of leave fellowships for instructors to work on the development of some aspect of their teaching. Perhaps only a centre with some feeling of security can start rocking the boat that way. Perhaps others are doing so but not talking about it yet. As teachers we are generally aware of the role of incentives in getting students to learn, yet we put up with situations (especially in universities) that sometimes punish good teachers for working on their teaching rather than publishing and securing research grants.

We are suggesting here that there is a largely unexplored approach in instructional development that might be more powerful than all the piecemeal direct applications of workshops, newsletters, and evaluation projects. This approach would be to seek to enhance the likelihood of rewards to instructors for teaching well done. All the other activities are by no means redundant under such a regime, but they cease being their own ends. Newsletters and libraries become vehicles for sensitizing faculties to the importance of quality teaching. Workshops and seminars help disseminate useful skills that faculty members can employ in developing their teaching. Evaluation becomes the means by which they monitor and demonstrate their competence. Research continues the search for new knowledge about teaching and learning, and even adds an element of academic respectability to the service unit - useful in getting listened to be colleagues. All this does not imply a "gung-ho let's change the world tomorrow" approach. Direction is a better word than approach. There is in this idea a broader purpose than any of the individual activities that an instructional development unit might provide.

There is, fortunately, growing awareness of this idea across the country. It is reflected for example in some of the deliberations of the AUCC Learning Effectiveness Committee and the CAUT Teaching Effectiveness Subcommittee. The latter is preparing a handbook in demonstrating teaching effectiveness which should be ready in about a year. This 
handbook will be accompanied by approaches to administrators concerning the recognition of such demonstration. This is very important, because there is no point asking instructors to offer evidence for its quality (evidence that was previously used to demonstrate the lack of quality!) if those who will make the decisions about tenure, promotions, or merit pay are not prepared (in both senses of the word) to accept it. Such recognition of demonstrated competence is of course the first part of any effective incentive system. In addition, CAUT and CLD are collaborating on a book on the whole question of evaluating teaching in higher education. ${ }^{7}$ It covers, for example, the question of institutional rewards for teaching in great detail, and is expected to be published early in 1975 .

In summary, then, no one involved in instructional development in Canadian higher education claims to have the patent medicine cure-all for every teaching and learning problem we might encounter. A variety of approaches is being followed. They vary according to the size and nature of the institutions and to what they see as their most pressing local needs. There is an obvious awareness - observed in contacts with many of the people involved - that there are larger issues. Rewards for good teaching are one example of a larger issue that can take many forms, from supportive and confidential applications of evaluations, to public statements by administrators, to promotions and raises.

\section{The Evolution of an Instructional Development Community}

The community has expressed itself most formally in three sectors, Quebec and Ontario universities, and the colleges. All the universities of Quebec plus the Universities of Ottawa and Moncton comprise the Comité interuniversitaire des Services de pédagogie. The committee serves several purposes. It is a chance to get together and share ideas, it is organizing a model for roving workshops for the "animation" of faculty members to use the services and to encourage other campuses to establish services. It also serves as a consultative agency to the Conference of Rectors and Principals. Indeed, the committee rendered obsolete the Conference's Subcommittee on Teaching Methods, and in return for the opportunity for consultation the Conference provides the secretariat for the Committee. The Ontario program will likely serve similar unifying functions once services become stronger on individual campuses. Instructional development, for reasons alluded to earlier, cannot be carried out in a vacuum. At the very least, one needs the solace of colleagues. The Canadian Community College Association has also provided a forum for collegial instructional development officers to get together. Psychologists teaching at the college level also met at the last two Canadian Psychological Association meetings to focus their concerns for the teaching of psychology.

The community extends across international boundaries as well. A group of about fifteen large university centres from the USA plus CLD have met once or twice a year and also exchange newsletters and word of special projects. CLD also maintains such contacts with similar centres growing in Europe and Australia. The European Association for the Study of Higher Education devoted its December 1973 Congress to the methodology of research in the study of higher education and invited several papers on instructional development.

${ }^{7}$ Knapper, Chris, Geis, George L., Pascal, Charles E., and Shore, Bruce M., (Eds.). Scaling the Ivory Tower: Appraising Teaching in Higher Education. In preparation (expected publication date: early 1975 by Clarke-Irwin, Toronto). 
Finally, in addition to traditional learned journals and associations concerned with higher education, a number of new ones are emerging dedicated primarily to the work of change agencies in higher education.

The lesson here is that instructional development is not a fly-by-night phenomenon. It reflects a realization by the higher education establishment (in the good sense of that word) that devoting a share of available resources to formal instructional development is a reasonable expenditure. The people involved in instructional development are often lone voices in the wilderness in their own institutions, but have the reassurance that there are others elsewhere with similar problems and successes. Sometimes this sense of community is the only thing that keeps us going when frustrations pile up, as they do from time to time. There is an element of crusading in the whole enterprise, and certainly a lot of proselytizing. The hard part is keeping in mind the admonition to tread gently.

\section{The Future of Instructional Development in Canada}

The progress so far has been good, and as good as anywhere else in the past five years. This is especially true at the college level. There are still too many universities where there is no one for an instructor to go to when he wants pedagogical help. There are still too many colleges with only one beleaguered professional development officer trying to do the whole job without a secretary or even a budget to hire temporary help for special occasions.

Despite the problems, the outlook is good. First steps tend to be shaky; surefootedness and nimbleness come later. We are not far from finding in this country a variety of thriving pedagogical services. Stories have been told about students suing colleges for not teaching them. The colleges win, because the issues are not so simplistic. Governments and institutions are very sensitive to the demands of students for effective teaching. There is a growing concern for looking at educational outputs (e.g., learning) as well as inputs (e.g., costs). This last point is one of the main distinctions between instructional development agencies, on one hand, and more traditional departments of higher education and institutional research units on the other. ${ }^{8}$ The improvement of evaluation techniques is an important part of the ability to examine educational outputs at all. These two approaches to the study of higher education are very much complementary.

In short, then, the importance of accountability in higher education, budget limitations or not, should auger well for the continued growth of instructional development in Canada. And the biggest winners will hopefully be students and teachers. ${ }^{9}$

${ }^{8}$ Shore, Bruce M., and Donald, Janet G. "Pedagogical Services: CLD's Friends and Relatives." Learning and Development, V, 6 (April/May, 1974), 1-4.

${ }^{9}$ For other useful references see Sheffield, Edward F. "Approaches (Mostly Elsewhere) to the Improvement of Teaching in Higher Education." Improving College and University Teaching, XXI, 1(1973), also Stoa (The Canadian Journal of Higher Education), 1II, 1(1973), 65-74.

Also see Konrad, Abram G. "Staff Development in Western Canadian Colleges." Stoa (The Canadian Journal of Higher Education), III 1(1973), 47-52. 